\title{
A validated stability-indicating HPLC method for determination of brimonidine tartrate in BRI/PHEMA drug delivery systems
}

CrossMark

Jianguo Sun ${ }^{1,3}$, Xiuwen Zhang ${ }^{2}$ and Taomin Huang ${ }^{2 *}$

\begin{abstract}
Background: A simple, rapid and accurate stability-indicating reverse phase high performance liquid chromatography (RP-HPLC) was developed and validated for the determination of brimonidine tartrate in brimonidine tartrate/ poly(2-hydroxyethyl methacrylate) (BRI/PHEMA) drug delivery contact lenses and pharmaceutical formulations.

Results: Optimum chromatographic conditions for separating brimonidine tartrate from other impurities in the leaching liquor of BRI/PHEMA drug delivery contact lenses or pharmaceutical formulations have been achieved by using a Diamonsil C18 column $(150 \mathrm{~mm} \times 4.6 \mathrm{~mm}, 5 \mu \mathrm{m})$ as a stationary phase and a mixture solution of phosphate buffer (10 mM, pH3.5) containing 0.5\% triethlamine and methanol $(85: 15, \mathrm{v} / \mathrm{v})$ as a mobile phase at a flow rate of $1 \mathrm{~mL} / \mathrm{min}$. The theoretical plates for the brimonidine tartrate measurement were calculated to be 8360 when detection was performed at $246 \mathrm{~nm}$ using a diode array detector. The proposed method was validated in accordance with ICH guidelines with respect to linearity, accuracy, precision, robustness, specificity, limit of detection and quantitation. Regression analysis showed a good correlation $\left(R^{2}>0.999\right)$ for brimonidine tartrate in the concentration range of $0.01-50 \mu \mathrm{g} / \mathrm{mL}$. The peak purity factor is $\geq 980$ for the analyte after all types of stress tests, indicating an excellent separation of brimonidine tartrate peak from other impurities. The measurement course could be completed within 10 min, which was very quick, effective and convenient.
\end{abstract}

Conclusions: Overall, the proposed stability-indicating method was suitable for routine quality control and drug analysis of brimonidine tartrate in BRI/PHEMA drug delivery contact lenses and other pharmaceutical formulations.

Keywords: Liquid chromatography, Method validation, Brimonidine tartrate, Impurities, Drug delivery system, Contact lens

\section{Introduction}

Glaucoma is an ocular disease characterized by elevated intraocular pressure (IOP) and progressive optic neuropathy, leading to visual loss [1]. Decreasing and maintaining IOP by means of topical drug administration is the most direct and preferred treatment options to treat glaucoma. Brimonidine [5-bromo-6-(2-imidazolidinylideneamino) quinoxaline] is a highly selective $\alpha_{2}$-adrenoceptor agonist which can lower IOP and is approved for topical ocular administration for glaucoma treatments.

\footnotetext{
*Correspondence: taominhuang@126.com

2 Department of Pharmacy, Eye \& ENT Hospital, Shanghai Medical

College, Fudan University, Shanghai 200031, China

Full list of author information is available at the end of the article
}

Brimonidine tartrate (shown in Fig. 1) can not only lower IOP [2], but also protective optic nerve and thus limit the progression of visual loss in glaucoma [3]. However, the topical administration of brimonidine tartrate eye drops has low bioavailability through the cornea (1-7\%), and the remaining drug which enters systemic circulation can cause side effects [4]. Moreover, the application of ophthalmic drugs as drops results in a fluctuating concentration of drug penetrated into the cornea, and thus limits their therapeutic efficacy. It is difficult to achieve sustained therapeutic level of topically applied ophthalmic drugs in the eye because of structural and metabolic barriers, especially in the vitreous and retina. Therefore, new types of drug delivery systems are highly 
<smiles>O=C(O)C(O)C(O)C(=O)O</smiles>

Fig. 1 The structural formulae of brimonidine tartrate

desirable to increase drug delivery efficacy and reduce side effects, and to improve the drug therapeutic effect by controlling the rate of drug delivery.

Hydrogel-based contact lenses were used to prepare local drug delivery systems for treating glaucoma which consisted of a swellable polymer hydrogel and commonly used glaucoma drugs [5-7]. Poly(2-hydroxyethyl methacrylate) (PHEMA) hydrogels are well known as materials for contact lenses and ophthalmic implanted materials [8, 9], and their potential uses as drug delivery carriers have also been reported in recent research $[8,10]$. Ophthalmic drug delivery via PHEMA contact lenses could improve the delivery efficiency by increasing the residence time of drug on the eye surface and simultaneously reducing drug wastage and side effects [11]. Brimonidine tartrate can be delivered to the post-lens tear film by wearing a PHEMA contact lens which was prepared by molecular imprinting polymerizing technique [12], or only by simple soaking absorption and release method [13]. Drug could be sustainably released from the PHEMA contact lens for several hours or days. Thus, the drug should be stable in the contact lens. In the in vitro drug release course, apart from brimonidine tartrate, some impurities, such as unreacted 2-hydroxyethyl methacrylate, cross linker or polymerization initiator, might be released into the leaching liquor, which might affect the measurement of the purpose brimonidine tartrate. Therefore, the stability study of brimonidine tartrate is urgent and it is necessary to develop a rapid and efficient method to quantitatively analyze brimonidine tartrate released from BRI/PHEMA contact lenses.

Various analytical methods have been reported for the determination of brimonidine tartrate, including electroanalytical method [14, 15], spectrophotometric method [16], highly sensitive gas chromatography/ mass spectrometric assay [17], high-performance thin layer chromatography (HPTLC) [18], high-performance liquid chromatography (HPLC) [19-21], liquid chromatography-mass spectrometry (LC-MS) $[22,23]$ and high performance liquid chromatography-tandem mass spectrometry (HPLC-TMS) [24]. However, some of the above-described methods are limited in either low sensitivity or specificity. Furthermore, extensive survey revealed that no stability-indicating high performance liquid chromatography (HPLC) method has been reported including major pharmacopoeias such as USP, EP, JP and BP for the simultaneous determination of brimonidine tartrate and other impurities. Therefore, it is very promising and urgent to develop a stability-indicating HPLC method to simultaneously determine brimonidine tartrate and its impurities in the leaching liquor of BRI/PHEMA contact lenses. So we first prepared BRI/PHEMA contact lenses by photopolymerization of 2-hydroxyethyl methacrylate, brimonidine tartrate and cross linker assisted by polymerization initiator. Some leaching liquor of BRI/PHEMA contact lenses in the drug release course was collected and then a rapid and efficient RP-HPLC method was developed for the determination of brimonidine tartrate and other impurities in the leaching liquor of BRI/PHEMA contact lenses. Linearity, accuracy, precision, specificity, robustness, LOD and LOQ of the proposed method were demonstrated based on method validation.

\section{Methods \\ Materials and reagents}

This process used 2-hydroxyethyl methacrylate (HEMA) (J \& K Chemical Ltd. Shanghai, China). Poly (ethylene glycol) dimethacrylate (PEG-DMA, MW700), brimonidine tartrate (Lot No.: LA50Q41, BRI) and 2-hydroxy1-[4-(hydroxyethoxy) phenyl]-2-methl-1-propanone (D2959) were purchased from Sigma-Aldrich (Shanghai, China). Brimonidine tartrate eye drops (Alphagan, 0.2\% brimonidine tartrate, $\mathrm{w} / \mathrm{w}$ ) were obtained from Allergan Pharmaceuticals (Republic of Ireland). Potassium dihydrogen phosphate $\left(\mathrm{KH}_{2} \mathrm{PO}_{4}\right)$ was obtained from Sinopharm Chemical Reagent Co. Ltd. (Shanghai, China). Phosphoric acid was obtained from Lingfeng Chemical Reagent Co. Ltd. (Shanghai, China). Triethlamine (HPLC grade) was obtained from Fisher scientific (New Jersey, USA). HPLC-grade methanol was obtained from TEDIA (OH, USA). All above chemicals were analytical grade and used as received. All solutions were prepared in Milli-Q deionized water from a Millipore water purification system (Bedford, MA, USA). Mobile phase was filtered using $0.45 \mu \mathrm{m}$ nylon filters from Millipore Co. (MA, USA) by an Auto Science AP-01P system from Tianjin Automatic Science Instrument Co. LTD (China).

\section{Preparation of sample solutions}

The BRI/PHEMA contact lens was prepared by a UV light polymerization reaction as reported previously $[9$, 25]. Briefly, $6 \mathrm{~g}$ of 2-hydroxyethyl methacrylate (HEMA) monomer solution was mixed with $90 \mathrm{mg}$ of brimonidine tartrate, $180 \mathrm{mg}$ of PEG-DMA as a cross linker and $18 \mathrm{mg}$ of $\mathrm{D} 2959$ in a $15-\mathrm{mL}$ brown glass bottle and the mixture was gently stirred under $\mathrm{N}_{2}$ gas for $20 \mathrm{~min}$. A 
polydimethylsiloxane (PDMS) mold which has a spherical cavity was used to prepare a PHEMA contact lens. The mixture solution was injected into the PDMS mold and the upper mold was slowly covered onto the lower mold to remove air bubble. Then the mold was placed vertically in UV light $(365 \mathrm{~nm}, \mathrm{SB}-100 \mathrm{P} / \mathrm{F}$, Spectronics Corporation, USA) for $30 \mathrm{~min}$ to polymerize a BRI/ PHEMA composite film. The film was peeled from the mold and then carefully tailored into a contact lens. As comparison, the pure PHEMA contact lens was prepared similarly by the same method.

ABRI/PHEMA contact lens sample ( $0.2 \mathrm{~g})$ was placed into a $50-\mathrm{mL}$ plastic container with $30 \mathrm{~mL}$ of phosphate buffered saline (PBS) solution ( $\mathrm{pH}=7.4)$. The container was firmly capped with the lid and shaken at $37^{\circ} \mathrm{C}$ and a speed of $50 \mathrm{rpm}$ in the DKZ-3B shaker (Shanghai Yiheng Scientific instruments Co. Ltd.). At $1 \mathrm{~h}, 24 \mathrm{~h}$ and 7 day, $1 \mathrm{~mL}$ of the leaching liquor of the BRI/PHEMA contact lens was collected and the same volume was supplied. The $\mathrm{pH}$ of the leaching liquor was adjusted to 3.5 with $1 \mathrm{M} \mathrm{HCl}$ and filtered with a $0.45 \mu \mathrm{m}$ nylon filter and centrifuged twice to remove any undissolved substance before the quantitative measurement by HPLC. Similarly, the leaching liquor of a pure PHEMA contact lens was also collected as a blank control.

\section{Preparation of standard solution}

A standard stock solution of brimonidine tartrate $(1 \mathrm{mg} /$ $\mathrm{mL}$ ) was prepared using the mobile phase. Series working solutions were diluted to the desired concentration for linearity, accuracy, precision, solution stability and robustness etc.

\section{Equipment and chromatographic conditions}

Samples were analyzed on an Agilent 1100 HPLC system (Agilent Technologies, Palo Alto, CA, USA), attached with a G1311A quaternary pump, a G1312A vacuum degasser, and a G1315B DAD detector. The detector wavelength was fixed at $246 \mathrm{~nm}$ and the peak areas were integrated automatically using the Hewlett-Packard ChemStation software program [16]. Other apparatus included an ultrasound generator and a SevenEasy $\mathrm{pH}$ meter (Mettler Toledo, USA) that was equipped with a combined glass-calomel electrode. A Diamonsil C18 column $(150 \mathrm{~mm} \times 4.6 \mathrm{~mm}, 5 \mu \mathrm{m})$ was maintained at $30{ }^{\circ} \mathrm{C}$. The mobile phase was composed of a phosphate buffer (10 mM, pH 3.5) containing $0.5 \%$ triethlamine and methanol $(85: 15, \mathrm{v} / \mathrm{v})$. The flow rate of the mobile phase was set at $1 \mathrm{~mL} / \mathrm{min}$. Measurements were made with $20 \mu \mathrm{L}$ of injection volume. For the analysis of the forced degradation samples, the photodiode array detector was used in a scan mode with a range of $200-400 \mathrm{~nm}$. The peak homogeneity was expressed in terms of peak purity factor and was obtained directly from the spectral analysis report using the above-mentioned software.

\section{Method validation}

The proposed method was validated according to $\mathrm{ICH}$ guidelines [26] including linearity, accuracy, precision, specificity, robustness, limit of detection (LOD) and limit of quantitation (LOQ). The linearity test solution was freshly prepared by diluting the stock standard solution with mobile phase. The linearity was tested at six levels ranging in $0.01-50 \mu \mathrm{g} / \mathrm{mL}(0.01,0.1,0.5,1,10,25,50 \mu \mathrm{g} /$ $\mathrm{mL}$ ) for brimonidine tartrate. Each solution was prepared in triplicate. Calibration curves were plotted between the responses of peak versus analyte concentrations. The coefficient correlation, slope and intercept of the calibration curve were calculated. Accuracy of the developed method was determined by standard addition method. For this purpose, known quantities of brimonidine tartrate $(0.1,10,50 \mu \mathrm{g} / \mathrm{mL})$ were supplemented to the sample solution previously analyzed. Then, the experimental and true values were compared. The precision was tested by intra-day and inter-day precision at three level concentrations $(0.1,10,50 \mu \mathrm{g} / \mathrm{mL})$. Intra-day precision was studied on the same day $(n=5)$. And inter-day precision was determined by performing the same procedures on three consecutive days. Percentage relative standard deviation (RSD \%) for peak areas was then calculated to represent precision. Specificity was the ability of the method to measure the analyte from the excipients and potential impurities. The specificity of the developed method was investigated in the presence of potential impurities. To determine the robustness of the developed method, the mobile phase composition, flow rate and $\mathrm{pH}$ value of buffer solution were deliberately changed. The effects of these changes on chromatographic parameters such as retention time, symmetry and number of theoretical plates were then investigated. LOD and LOQ values were determined at signal-to-noise $(\mathrm{S} / \mathrm{N})$ ratios of $3: 1$ and 10:1, respectively, by measuring a series of dilute solutions with known concentrations.

\section{Forced degradation studies}

Forced degradation studies were carried out using differently prescribed stress conditions such as thermolytic, photolytic, acid, base hydrolytic and oxidative stress conditions according to a previously reported method [27-29].

\section{Acid degradation}

For this purpose, $2.5 \mathrm{~mL}$ of the standard stock solution was transferred into a $100 \mathrm{~mL}$ volumetric flask. And then $2.5 \mathrm{~mL}$ of $5 \mathrm{M} \mathrm{HCl}$ was added into the flask, which was kept at $40{ }^{\circ} \mathrm{C}$ for $24 \mathrm{~h}$ in water bath. After completion of 
the acid stress, the solution was cooled in room temperature and neutralized by $5 \mathrm{M} \mathrm{NaOH}$ and the volume was completed up to the mark $(100 \mathrm{~mL})$ with mobile phase.

\section{Alkali degradation}

In a $100-\mathrm{mL}$ volumetric flask, $2.5 \mathrm{~mL}$ of the standard stock solution was added. Then $2.5 \mathrm{~mL}$ of $5 \mathrm{M} \mathrm{NaOH}$ was also added into the flask and the solution was kept at $40{ }^{\circ} \mathrm{C}$ for $2 \mathrm{~h}$ in water bath. The solution was cooled in room temperature and neutralized by using $5 \mathrm{M} \mathrm{HCl}$ and diluted to the mark $(100 \mathrm{~mL})$ with mobile phase.

\section{Oxidative degradation}

For this purpose, $2.5 \mathrm{~mL}$ of the standard stock solution was transferred into $100-\mathrm{mL}$ volumetric flask. $2.5 \mathrm{~mL}$ of $6 \% \mathrm{H}_{2} \mathrm{O}_{2}$ was added into the flask and keep at $40{ }^{\circ} \mathrm{C}$ for $24 \mathrm{~h}$ in water bath. Then, the solution was cooled in room temperature and diluted to the mark $(100 \mathrm{~mL})$ with mobile phase.

\section{Thermal degradation}

Thermal degradation study was performed at two different temperatures: $40{ }^{\circ} \mathrm{C}$ in an electric-heated thermostatic water bath (DK-S28) and $105{ }^{\circ} \mathrm{C}$ in oven (dry heat thermolysis, DGH-9203A), which were both from Shanghai Jing Hong Laboratory Instrument Co. Ltd. (China). For thermal degradation at $40{ }^{\circ} \mathrm{C}, 2.5 \mathrm{~mL}$ of the standard stock solution was transferred into $100-\mathrm{mL}$ volumetric flask and kept at $40{ }^{\circ} \mathrm{C}$ in water bath for 120 and $240 \mathrm{~h}$. The solution was cooled in room temperature and the volume was completed up to the mark with mobile phase. Dry heat thermolysis was conducted by taking standard brimonidine tartrate in Petri dish and heated in oven at
$105{ }^{\circ} \mathrm{C}$ for $7 \mathrm{~h}$. After completion of the stress, the powder was dissolved and diluted with mobile phase. Photo stability studies were performed on a photo stability test chamber.

\section{Photolytic degradation}

Photolytic degradation study was conducted by exposing samples in a photo-stability test chamber (Pharma 500-L, Weiss Technik UK Ltd. Germany) at 1.2 million lux hour for light and $200 \mathrm{Wh} / \mathrm{m}^{2}$ for ultraviolet region. After photolytic degradation, samples were diluted with mobile phase to achieve a concentration of $25 \mu \mathrm{g} / \mathrm{mL}$ and injected into the HPLC measurement system.

\section{Results and discussion Preparation of BRI/PHEMA contact lens}

In the preparation course of a BRI/PHEMA contact lens, the monomer HEMA and the PEG-DMA were copolymerized by initiating with a UV light free radical initiator D2959. Using this initiator system, a PHEMA film can be obtained at room temperature. The BRI/PHEMA film prepared using UV-light copolymerization was visually transparent, indicating brimonidine tartrate was well dispersed in the composite film. The resultant PHEMA and BRI/PHEMA films could be tailored into hard contact lenses which are shown in Fig. 2. The hard contact lens could further form soft-hydrogel contact lens after swelled in water.

A range of UV light radiation time (10-40 $\mathrm{min})$ was tested for the HEMA polymerization, and time of $30 \mathrm{~min}$ was found to be sufficient to obtain a BRI/PHEMA film with smooth surface. When the BRI/PHEMA contact lens sample was leached in PBS solution $\left(\mathrm{pH}=7.4,37^{\circ} \mathrm{C}\right)$
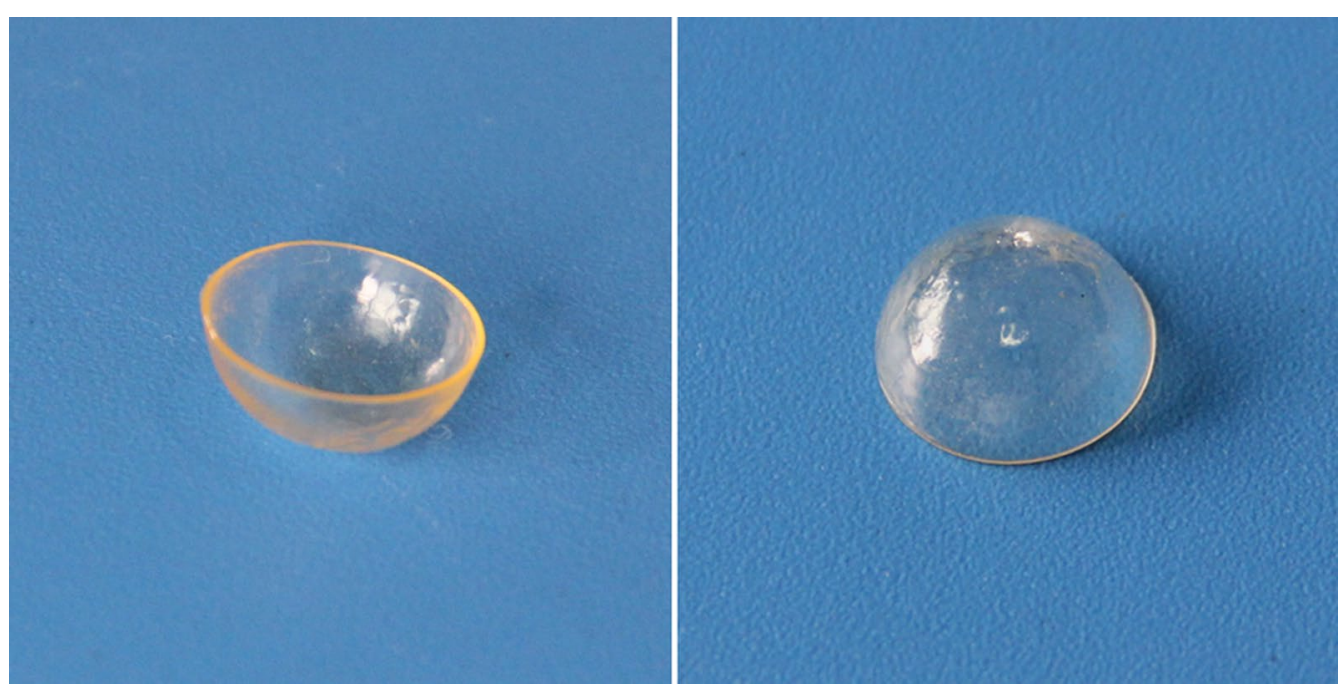

Fig. 2 Photos of hard contact lens 
for 1 week, the purpose sample solution was collected for the quantitative analysis of brimonidine tartrate loaded in the BRI/PHEMA contact lenses.

\section{Optimization of the chromatographic system}

The main objective of this work was to develop a stability-indicating HPLC method for determination of brimonidine tartrate within a short run time between 3-10 min and symmetry between 0.80 and 1.20 . The pKa of brimonidine is 7.4, it will be substantially ionized at $\mathrm{pH}$ below 6.5. Therefore, brimonidine tartrate can be ionized as brimonidine positive ion in the mobile phase (pH 3.5). UV spectrum (Fig. 3a) showed that brimonidine tartrate has a characteristic absorption peak at $245.9(\sim 246) \mathrm{nm}$. The chromatographic peak of brimonidine positive ion was about 4.3 min which was shown in Fig. 3b. Chromatograms of brimonidine tartrate in commercial ophthalmic solution and BRI/PHEMA formulation were shown in Fig. 3c, d, respectively. The content of brimonidine tartrate was calculated according to the peak area of brimonidine tartrate (about $4.3 \mathrm{~min}$ ) in this study.

Brimonidine tartrate has high ratio of carbon to heteroatom and has conjugated bond. Therefore, they can be separated through C18 stationary phase mainly based on their overall hydrophobicity. Brimonidine tartrate can also be separated using phenyl-hexyl stationary phase
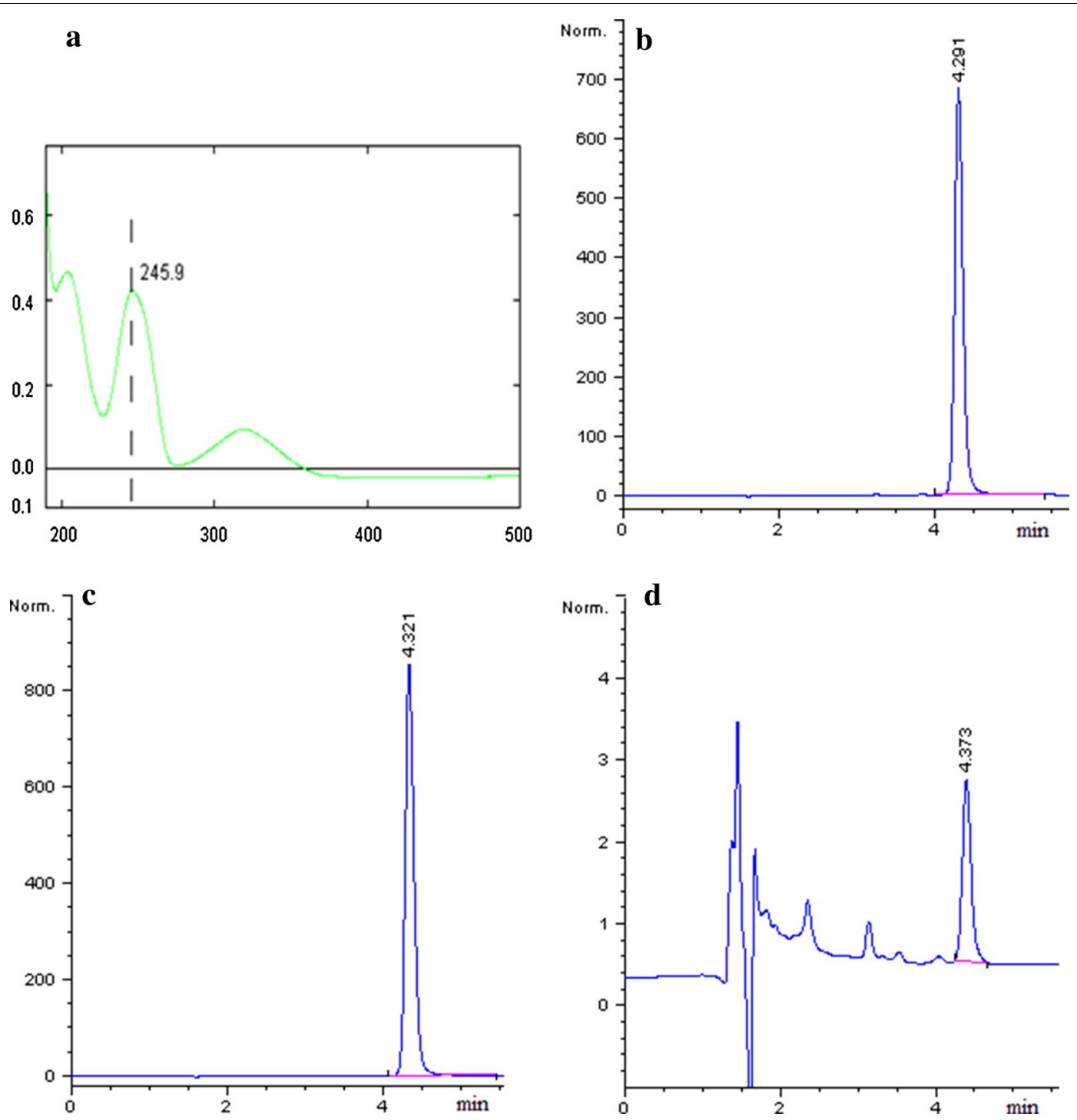

Fig. 3 The UV spectrum and chromatograms of brimonidine tartrate. a UV spectrum of brimonidine tartrate; $\mathbf{b}$ chromatogram for separation of brimonidine tartrate in standard solution; c chromatogram of brimonidine tartrate in commercial ophthalmic solution; $\mathbf{d}$ chromatogram of brimonidine tartrate in BRI/PHEMA formulation 
considering their $\pi$ electrons involving $\pi-\pi$ interactions. So they may be separated using cyano stationary phase.

The stationary and mobile phases play an important role on theoretical plates, peak shape, symmetry and resolution. To obtain symmetrical peaks with better resolution and no peak impurity, various chromatographic conditions were investigated and optimized for the determination of brimonidine tartrate, such as mobile phases with different composition, $\mathrm{pH}$ and stationary phases with different packing material etc. Attempts were made by using three kinds of HPLC columns (Agilent Zorbax Eclipse XDB C18, Agilent Eclipse Plus Phenyl-Hexyl and Diamonsil C18 column) with different mobile phase compositions and ratios. In all of the proceeding columns, broad characteristic peaks were obtained though using different ratios (20:80, 40:60, 50:50, 70:30, 80:20) of methanol/acetonitrile and water. No improvement of peak shapes was obtained even when the temperature of column was enhanced to $40{ }^{\circ} \mathrm{C}$. Some data of composition optimization of mobile phases were shown in Table 1, in which a Diamonsil C18 column was used.

As demonstrated in Table 1, the theoretical plates with the mixture solution of methanol or acetonitrile with water as a mobile phase were below 1000 which indicated poor column chromatography separation power. The peak symmetry and peak shape were all poor with the above two kinds of mixture solutions, which might be attributed to low polarity of the mobile phase. So some phosphate buffer with different concentration $(10,25$ or $50 \mathrm{mM})$ was used to improve polarity of the mobile phase, which resulted in a narrowed peak. However, the peak shape and peak symmetry were still not satisfactory. So some triethylamine (as silanol blocker) was further added to the above polar mobile phase to improve the separation of brimonidine tartrate with other impurities. Finally, the mixture solution of phosphate buffer $(10 \mathrm{mM})$, trimethylamine $(0.5 \%, \mathrm{v} / \mathrm{v})$ and methanol $(15 \%, \mathrm{v} / \mathrm{v})$ was demonstrated to be the suitable mobile phase for the improvement of peak shape and peak symmetry. With exception of the composition of mixture solution, buffer $\mathrm{pH}$ was also found to be critical in the analyte separation and method optimization.

Table 1 The optimisation of the mobil phases of solvent ratios with the Diamonsil C18 column

\begin{tabular}{llll}
\hline Mobile phase & $\begin{array}{l}\text { Theoretical } \\
\text { plates }(\mathbf{N})\end{array}$ & Symmetry & $\begin{array}{l}\text { Peak } \\
\text { shape }\end{array}$ \\
\hline Methanol:water $=15: 85$ & 476 & 0.78 & - \\
Acetonitrile:water $=15: 85$ & 607 & 0.70 & - \\
$0.010 \mathrm{M} \mathrm{KH}_{2} \mathrm{PO}_{4}:$ water $=15: 85$ & 6483 & 0.63 & - \\
$0.025 \mathrm{M} \mathrm{KH}_{2} \mathrm{PO}_{4}:$ water $=15: 85$ & 6258 & 0.61 & - \\
$0.050 \mathrm{M} \mathrm{KH}_{2} \mathrm{PO}_{4}:$ water $=15: 85$ & 6616 & 0.66 & - \\
\hline
\end{tabular}

-, poor peak shape
The effect of buffer $\mathrm{pH}$ on retention time was related with the ionization form of the solute. A series of mixture solutions with different $\mathrm{pH}$ values $(2.5,2.8,3.0,3.5,4.0,5.0$, 6.0, 7.0 and 8.0) were employed to investigate the retention time and resolution of brimonidine tartrate with other impurities in pharmaceutical formulation, in which the other chromatographic parameters were kept unchanged, including a Diamonsil C18 column and the fixed mobile phase composition of phosphate buffer $(10 \mathrm{mM})$, trimethylamine $(0.5 \%, \mathrm{v} / \mathrm{v})$ and methanol $(15 \%, \mathrm{v} / \mathrm{v})$.

As shown in Table 2, a buffer solution with $\mathrm{pH}$ of 3.5 was found to be optimal with more theoretical plates $(\geq 8360)$, narrow peak $(+++)$, high peak symmetry $(0.95)$ and short retention time (4.3, between 3 and $10 \mathrm{~min}$ ), which was then selected for the following experiments. Based on the optimal mobile phase, a highly symmetrical and sharp characteristic peak of brimonidine tartrate was further obtained on Diamonsil C18 column (with better resolution, peak shapes and theoretical plates).

\section{Method validation}

The developed chromatographic method was validated using $\mathrm{ICH}$ guidelines. Validation parameters included linearity, accuracy, precision, specificity, robustness, LOD and LOQ.

\section{Linearity}

Linearity was verified by a triplicate analysis of different concentrations of brimonidine tartrate solution. As a result, the linear regression equation was found to be $\mathrm{Y}=103.42 \mathrm{X}+2.83\left(\mathrm{R}^{2}=0.9998, n=7,0.01-50 \mu \mathrm{g} / \mathrm{mL}\right)$ for brimonidine tartrate. In which, $\mathrm{Y}$ was the dependent variable, $\mathrm{X}$ was independent variable, 103.42 was slope which showed change in dependent $(\mathrm{Y})$ variable per unit change in independent $(\mathrm{X})$ variable; 2.83 was the $\mathrm{Y}$-intercept i.e., the value of $Y$ variable when $X=0$. The linearity

Table 2 The optimisation of the pH of phosphate buffer (buffer:methanol is 85:15)

\begin{tabular}{lllll}
\hline $\begin{array}{l}\text { Mobile } \\
\text { phase }\end{array}$ & $\begin{array}{l}\text { Theoretical } \\
\text { plates }(\mathbf{N})\end{array}$ & Symmetry & $\begin{array}{l}\text { Retention time } \\
\left(\mathbf{t}_{\mathbf{R}}\right)(\mathbf{m i n})\end{array}$ & $\begin{array}{l}\text { Peak } \\
\text { shape }\end{array}$ \\
\hline $\mathrm{pH} \mathrm{2.5}$ & 9485 & 0.85 & 5.020 & + \\
$\mathrm{pH} 2.8$ & 8119 & 0.90 & 4.273 & +++ \\
$\mathrm{pH} \mathrm{3.0}$ & 8218 & 0.93 & 4.270 & +++ \\
$\mathrm{pH} \mathrm{3.5}$ & 8360 & 0.95 & 4.276 & +++ \\
$\mathrm{pH} \mathrm{4.0}$ & 8076 & 0.90 & 4.262 & +++ \\
$\mathrm{pH} \mathrm{5.0}$ & 7774 & 0.90 & 4.242 & +++ \\
$\mathrm{pH} 6.0$ & 7551 & 0.90 & 4.241 & +++ \\
$\mathrm{pH} \mathrm{7.0}$ & 7338 & 0.91 & 4.268 & +++ \\
$\mathrm{pH} 8.0$ & 7178 & 0.88 & 7.861 & + \\
\hline,+ good peak shape & & &
\end{tabular}

+ , good peak shape 
of developed chromatographic method was validated to be very good.

\section{Accuracy}

Accuracy of the developed method was determined by analyzing samples before and after adding some known amount of brimonidine tartrate. The acceptable recovery was set as between 97.0 and $103.0 \%$ and the results of accuracy confirmation of the proposed HPLC method were shown in Table 3.

The developed analytical method had a good accuracy with overall recovery rates in the range of $97.9-99.9 \%$ for the analyte with RSDs below $1.8 \%$, indicating that the proposed method was to be highly accurate and suitable for intended use.

\section{Precision}

The precision was evaluated by analyzing the standard solutions of brimonidine tartrate at three concentrations under the optimal conditions. It was considered at two levels: five times in one day for repeatability (intra-days) and on three consecutive days for intermediate precision (inter-days). The corresponding results were expressed as the relative standard deviation (RSD) and mean recovery of a series of measurements. The calculated RSD values of the intra-day and inter-day assays were $<1.0$ and $1.2 \%$, respectively. The results of intra-day and inter-day precision of the proposed HPLC method were shown in Table 4. The results also demonstrated that brimonidine tartrate was stable in solution and the developed analytical method had high precision and was suitable for intended use.

\section{Robustness}

Robustness was validated by slightly varying the chromatographic conditions. The chromatographic conditions and corresponding results were shown in Tables 5 . No obvious effects on the chromatographic parameters were observed in all of the deliberately varied chromatographic conditions (different flow rates, compositions of mobile phase and buffer $\mathrm{pH}$ ).

\section{$\angle O D$ and $L O Q$}

Based on a signal-to-noise ratio of 3:1, LOD was found to be $0.1 \mu \mathrm{g} / \mathrm{mL}$ for brimonidine tartrate. LOQ with a

Table 3 Accuracy of the proposed HPLC method

\begin{tabular}{lcll}
\hline $\begin{array}{l}\text { Spiked con. } \\
(\boldsymbol{\mu g} / \mathbf{m L})\end{array}$ & $\begin{array}{l}\text { Measured con. } \\
(\boldsymbol{\mu} \mathbf{g} / \mathbf{m L}) \pm \text { SD }\end{array}$ & Accuracy (\%) & RSD (\%) \\
\hline 0.1 & $0.098 \pm 0.002$ & 97.9 & 1.8 \\
5 & $4.98 \pm 0.02$ & 99.7 & 0.4 \\
50 & $49.96 \pm 0.32$ & 99.9 & 0.6 \\
\hline
\end{tabular}

$S D$ standard deviation, $R S D$ relative standard deviation, Con. concentration
Table 4 Intra-day and inter-day precision of the proposed HPLC method $(n=5)$

\begin{tabular}{lll}
\hline $\begin{array}{l}\text { Actual con. } \\
(\boldsymbol{\mu g} / \mathrm{mL})\end{array}$ & $\begin{array}{l}\text { Intra-day precision } \\
\text { Measured } \\
\text { con. } \pm \text { SD; RSD }(\%)\end{array}$ & $\begin{array}{l}\text { Inter-day precision } \\
\text { Measured } \\
\text { con. } \pm \text { SD; RSD (\%) }\end{array}$ \\
\hline 0.1 & $0.098 \pm 0.002 ; 1.5$ & $0.099 \pm 0.003 ; 1.5$ \\
5 & $4.98 \pm 0.02 ; 0.4$ & $4.98 \pm 0.02 ; 2.1$ \\
50 & $49.96 \pm 0.32 ; 0.6$ & $49.98 \pm 0.02 ; 1.3$ \\
\hline
\end{tabular}

$S D$ standard deviation, $R S D$ relative standard deviation, Con. concentration

signal-to-noise of 10:1 was found to be $0.01 \mu \mathrm{g} / \mathrm{mL}$ for brimonidine tartrate.

\section{Specificity}

Specificity was investigated by using photodiode array detection to ensure the homogeneity and evaluate peak purity which was evaluated at different stress conditions (acid, base, oxidation, thermal and photolytic) for brimonidine tartrate. The results were shown in Fig. 4.

Although several impurities and degradation products were detected, there was no influence on the main ingredients. The peak purity factor was more than 980 for drug product (Table 6), which further confirmed the specificity of this method.

\section{Forced degradation study}

All the stress conditions applied were enough to degrade brimonidine tartrate and other impurities in the pharmaceutical formulation. The results of stress studies are shown in Fig. 4 and Table 6. Brimonidine tartrate was degraded and remained $\sim 96.5 \%$ when $5 \mathrm{M} \mathrm{HCl}$ was used at $40{ }^{\circ} \mathrm{C}$ for $24 \mathrm{~h}$. Brimonidine tartrate remained $~ 95.6 \%$ when $5 \mathrm{M} \mathrm{NaOH}$ was used at $40{ }^{\circ} \mathrm{C}$ for $2 \mathrm{~h}$. Brimonidine tartrate was degraded and only remained $\sim 42.4 \%$ under $6 \% \mathrm{H}_{2} \mathrm{O}_{2}$ at $40{ }^{\circ} \mathrm{C}$ for $24 \mathrm{~h}$. The results of thermal stress showed that brimonidine tartrate was stable for $120 \mathrm{~h}$ under thermal stress $\left(40\right.$ and $\left.90{ }^{\circ} \mathrm{C}\right)$, even stable for $7 \mathrm{~h}$ under dry heat stress $\left(105^{\circ} \mathrm{C}\right)$. Brimonidine tartrate was not degraded substantial under photolytic stress. From these stress studies it was thus concluded that brimonidine tartrate was not stable in strong basic, strong acidic, especially oxidative conditions, but stable in thermal, dry heat and photolytic conditions. These results demonstrated that brimonidine tartrate could be used in the BRI/PHEMA drug delivery contact lens. The developed method effectively separated brimonidine tartrate from the impurities (Fig. 4). Therefore, the developed method can be considered highly specific for intended use.

\section{Application of the developed method}

Application of the developed method was checked by analyzing brimonidine tartrate in commercially available 
Table 5 Robustness of the developed analytical method

\begin{tabular}{|c|c|c|c|c|}
\hline $\begin{array}{l}\text { Chromatographic } \\
\text { condition }\end{array}$ & Assay \% & $t_{R}(\min )$ & $\begin{array}{l}\text { Theoretical } \\
\text { plates }\end{array}$ & Symmetry \\
\hline Flow rate $\left(0.9 \mathrm{~mL} \mathrm{\textrm {min } ^ { - 1 } )}\right.$ & 98.0 & 4.747 & 8247 & 0.90 \\
\hline Flow rate $\left(1 \mathrm{~mL} \mathrm{~min}^{-1}\right)$ & 99.7 & 4.279 & 7910 & 0.90 \\
\hline Flow rate $\left(1.1 \mathrm{~mL} \mathrm{\textrm {min } ^ { - 1 } )}\right.$ & 102.7 & 3.868 & 7438 & 0.91 \\
\hline Methanol:buffer (12:88) & 98.3 & 5.109 & 8218 & 0.93 \\
\hline Methanol:buffer (15:85) & 99.7 & 4.270 & 7878 & 0.91 \\
\hline Methanol:buffer (18:82) & 97.5 & 3.040 & 6898 & 0.90 \\
\hline Buffer (pH 3.0) & 104.3 & 4.270 & 8218 & 0.93 \\
\hline Buffer (pH 3.5) & 100.1 & 4.276 & 8360 & 0.95 \\
\hline Buffer (pH 4.0) & 98.5 & 4.262 & 8076 & 0.90 \\
\hline
\end{tabular}

pharmaceutical formulations and the BRI/PHEMA formulation. The results of commercial eye drops are provided in Table 7 . The results showed high percentage recoveries and low RSD (\%) values for commercial brimonidine tartrate eye drops.

The measured concentrations of brimonidine tartrate after a BRI/PHEMA drug delivery contact lens was leached for $1 \mathrm{~h}, 24 \mathrm{~h}$ and 7 day were $0.05,0.04$ and
$0.01 \mu \mathrm{g} / \mathrm{mL}$, respectively. It showed that brimonidine tartrate can be sustained released from the contact lens without a substantial fluctuating concentration. Thus, it can improve drug therapeutic efficacy. The results further confirmed that the developed method was suitable for drug analysis of brimonidine tartrate in the BRI/ PHEMA drug delivery contact lenses and pharmaceutical formulations.

\section{Conclusion}

A rapid and efficient RP-HPLC method was developed for the estimation of brimonidine tartrate in the BRI/ PHEMA drug delivery contact lenses and pharmaceutical formulations. The proposed method was demonstrated to be linear, accurate, precise, robust and specific, based on method validation. Satisfactory results were obtained in separating the peaks of active pharmaceutical ingredients from the degradation products produced by forced degradation. Furthermore, the new method are cost-effective without the requirement of ion pairing and other derivatization agents, which are tend to adsorb very strongly on the stationary phase, resulting in difficulty in recovering initial column properties. Overall, the method

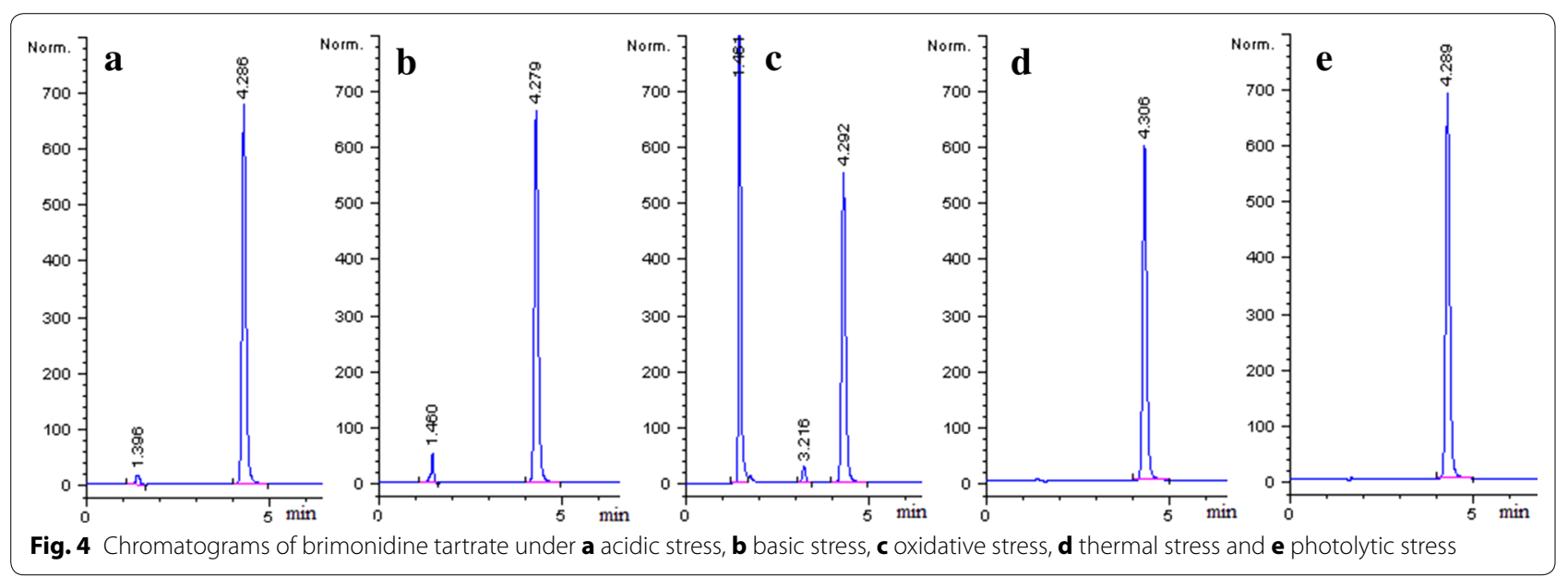

Table 6 Stress testing results of brimonidine tartrate in stock solution

\begin{tabular}{llcll}
\hline Nature of stress & Storage conditions & Time $(\mathbf{h})$ & Amount [remaining \pm SD (\%)] (PP) & Extent of decomposition \\
\hline $5 \mathrm{M} \mathrm{HCl}$ & $40{ }^{\circ} \mathrm{C}$ & 24 & $96.5 \pm 0.8(999.74)$ & A little \\
$5 \mathrm{M} \mathrm{NaOH}$ & $40{ }^{\circ} \mathrm{C}$ & 2 & $95.6 \pm 2.3(999.98)$ & A little \\
$6 \% \mathrm{H}_{2} \mathrm{O}_{2}$ & $40{ }^{\circ} \mathrm{C}$ & 24 & $42.4 \pm 0.5(999.74)$ & Substantial \\
Thermal & $40{ }^{\circ} \mathrm{C}$ & 120 & $99.3 \pm 0.2(999.99)$ & None \\
& $40{ }^{\circ} \mathrm{C}$ & 240 & $99.2 \pm 0.2(999.99)$ & None \\
Dry heat & $105^{\circ} \mathrm{C}$ & 7 & $99.4 \pm 0.2(999.85)$ & None \\
Photolytic & $12 \mathrm{million}$ lux hours and $200 \mathrm{~W} \mathrm{~h} / \mathrm{m}^{2}$ & & $99.3 \pm 0.2(999.99)$ & None
\end{tabular}

$n=3 ; \mathrm{PP}=$ peak purity factor, peak purity factor value in the range of 980-1000 indicates a homogeneous peak 
Table 7 Assay results of brimonidine tartrate in commercial eye drops $(n=3)$

\begin{tabular}{llll}
\hline Batch no. & Labled & Found & RSD (\%) \\
\hline E73767 & $10{\mathrm{mg} 5 \mathrm{~mL}^{-1}}$ & $9.74{\mathrm{mg} 5 \mathrm{~mL}^{-1}}^{-1}$ & 1.41 \\
E73506 & & $9.66{\mathrm{mg} 5 \mathrm{~mL}^{-1}}$ & 1.15 \\
\hline
\end{tabular}

is stability-indicating and can be used for routine analysis of brimonidine tartrate in quality control and any kind of stability and validation studies.

\section{Abbreviations}

BRI: brimonidine tartrate; HEMA: 2-hydroxyethyl methacrylate; BRI/PHEMA: brimonidine/Poly(2-hydroxyethyl methacrylate); IOP: intraocular pressure; PEGDMA: poly (ethylene glycol) dimethacrylate; PDMS: polydimethylsiloxane; LOD: limit of detection; LOQ: limit of quantitation; ICH: International Conference on Harmonisation; HPLC: high performance liquid chromatography.

\section{Authors' contributions}

TH designed the study, participated in discussing the results, and revised the manuscript. JS performed the assays and prepared the manuscript. XZ conducted the optimization and assay validation studies. All authors read and approved the final manuscript.

\section{Author details}

${ }^{1}$ Eye Institute, Eye \& ENT Hospital, Shanghai Medical College, Fudan University, Shanghai 200031, China. ${ }^{2}$ Department of Pharmacy, Eye \& ENT Hospital, Shanghai Medical College, Fudan University, Shanghai 200031, China. ${ }^{3}$ Key Laboratory of Myopia, NHFPC, and Shanghai Key Laboratory of Visual Impairment and Restoration, Fudan University, Shanghai 200031, China.

\section{Competing interests}

The authors declare that they have no competing interests.

\section{Availability of data and materials}

We have presented all our main data in the form of tables and figures. The datasets supporting the conclusions of the article are included within the article.

\section{Funding}

The authors were supported by grants from the Projects of Shanghai Natural Science Foundation (Grants No. 15ZR1405900). The sponsor or funding organization had no role in the design or conduct of this research.

\section{Publisher's Note}

Springer Nature remains neutral with regard to jurisdictional claims in published maps and institutional affiliations.

Received: 10 May 2017 Accepted: 6 July 2017

Published online: 11 July 2017

\section{References}

1. Weinreb RN (2007) Glaucoma neuroprotection: what is it? Why is it needed? Can J Ophthalmol 42(3):396-398

2. Cantor LB (2006) Brimonidine in the treatment of glaucoma and ocular hypertension. Ther Clin Risk Manag 2(4):337-346

3. WoldeMussie E, Ruiz G, Wijono M, Wheeler LA (2001) Neuroprotection of retinal ganglion cells by brimonidine in rats with laser-induced chronic ocular hypertension. Invest Ophthalmol Vis Sci 42(12):2849-2855

4. Ghate D, Edelhauser HF (2008) Barriers to glaucoma drug delivery. J Glaucoma 17(2):147-156
5. Bengani LC, Hsu KH, Gause S, Chauhan A (2013) Contact lenses as a platform for ocular drug delivery. Expert Opin Drug Del 10(11):1483-1496

6. Gupta H, Aqil M (2012) Contact lenses in ocular therapeutics. Drug Discov Today 17(9-10):522-527

7. Schultz CL, Poling TR, Mint JO (2009) A medical device/drug delivery system for treatment of glaucoma. Clin Exp Optom 92(4):343-348

8. Kakisu K, Matsunaga T, Kobayakawa S, Sato T, Tochikubo T (2013) Development and efficacy of a drug-releasing soft contact lens. Invest Ophthalmol Vis Sci 54(4):2551-2561

9. Xiang J, Sun J, Hong J, Wang W, Wei A, Le Q, Xu J (2015) T-style keratoprosthesis based on surface-modified poly (2-hydroxyethyl methacrylate) hydrogel for cornea repairs. Mater Sci Eng C Mater Biol Appl 50:274-285

10. Garcia-Millan E, Koprivnik S, Otero-Espinar FJ (2015) Drug loading optimization and extended drug delivery of corticoids from pHEMA based soft contact lenses hydrogels via chemical and microstructural modifications. Int J Pharm 487(1-2):260-269

11. Carvalho IM, Marques CS, Oliveira RS, Coelho PB, Costa PC, Ferreira DC (2015) Sustained drug release by contact lenses for glaucoma treatmenta review. J Control Release 202:76-82

12. Omranipour HM, Sajadi Tabassi SA, Kowsari R, Rad MS, Mohajeri SA (2015) Brimonidine imprinted hydrogels and evaluation of their binding and releasing properties as new ocular drug delivery systems. Curr Drug Deliv 12(6):717-725

13. Garcia Delpech S, Garcia Gomez S, Barreiro Rego A, Carrasco Luna J (2001) Brimonidine absorption and release from 1. Day acuvue disposable contact lenses. Arch Soc Esp Oftalmol 76(10):599-603

14. Radulovic V, Aleksic MM, Agbaba D, Kapetanovic V (2013) An electroanalytical approach to brimonidine at boron doped diamond electrode based on its extensive voltammetric study. Electroanalysis 25(1):230-236

15. Aleksic MM, Radulovic V, Agbaba D, Kapetanovic V (2013) An extensive study of electrochemical behavior of brimonidine and its determination at glassy carbon electrode. Electrochim Acta 106:75-81

16. Ibrahim F, El-Enany N, El-Shaheny RN, Mikhail IE (2015) Validated spectrofluorimetric and spectrophotometric methods for the determination of brimonidine tartrate in ophthalmic solutions via derivatization with NBD-Cl. Application to stability study. Luminescence 30(3):309-317

17. Acheampong A, Tang-Liu DD (1995) Measurement of brimonidine concentrations in human plasma by a highly sensitive gas chromatography/ mass spectrometric assay. J Pharm Biomed Anal 13(8):995-1002

18. Jain PS, Khatal RN, Jivani HN, Surana SJ (2011) Stability-indicating densitometric HPTLC analysis of brimonidine tartrate in the bulk drug and in eye drops. Jpc J Planar Chromat 24(2):166-171

19. Karamanos NK, Lamari F, Katsimpris J, Gartaganis S (1999) Development of an HPLC method for determining the alpha(2)-adrenergic receptor agonist brimonidine in blood serum and aqueous humor of the eye. Biomed Chromatogr 13(1):86-88

20. Acheampong AA, Shackleton M, Tangliu DDS (1995) Comparative ocular pharmacokinetics of brimonidine after a single-dose application to the eyes of albino and pigmented rabbits. Drug Metab Dispos 23(7):708-712

21. Narendra A, Deepika D, Annapurna MM (2012) Liquid chromatographic method for the analysis of brimonidine in ophthalmic formulations. E J Chem 9(3):1327-1331

22. Jiang SW, Chappa AK, Proksch JW (2009) A rapid and sensitive LC/MS/MS assay for the quantitation of brimonidine in ocular fluids and tissues. J Chromatogr B 877(3):107-114

23. Hassib ST, Elkady EF, Sayed RM (2016) Simultaneous determination of timolol maleate in combination with some other anti-glaucoma drugs in rabbit aqueous humor by high performance liquid chromatographytandem mass spectroscopy. J Chromatogr B 1022:109-117

24. Cantor LB, WuDunn D, Catoira-Boyle Y, Yung CW (2008) Absorption of brimonidine $0.1 \%$ and $0.15 \%$ ophthalmic solutions in the aqueous humor of cataract patients. J Glaucoma 17(7):529-534

25. Sun JG, Graeter SV, Tang J, Huang JH, Liu P, Lai YX et al (2014) Preparation of stable micropatterns of gold on cell-adhesion-resistant hydrogels assisted by a hetero-bifunctional macromonomer linker. Sci China Chem 57(4):645-653

26. Gowda N, Kumar P, Panghal S, Rajshree M (2010) ICH guidance in practice: validated reversed-phase HPLC method for the determination of active mangiferin from extracts of Mangifera indica Linn. J Chromatogr Sci 48(2):156-160 
27. Peraman R, Manikala M, Kondreddy VK, Yiragamreddy PR (2015) A stability-indicating RP-HPLC method for the quantitative analysis of meclizine hydrochloride in tablet dosage form. J Chromatogr Sci 53(5):793-799

28. Razzaq SN, Khan IU, Mariam I, Razzaq SS (2012) Stability indicating HPLC method for the simultaneous determination of moxifloxacin and prednisolone in pharmaceutical formulations. Chem Cent J 6(1):94
29. Huang TM, Chen NZ, Wang DL, Lai YH, Cao ZJ (2014) A validated stability-indicating HPLC method for the simultaneous determination of pheniramine maleate and naphazoline hydrochloride in pharmaceutical formulations. Chem Cent J 8(1):7

\section{Submit your manuscript to a SpringerOpen ${ }^{\circ}$ journal and benefit from:}

- Convenient online submission

- Rigorous peer review

- Open access: articles freely available online

- High visibility within the field

- Retaining the copyright to your article

Submit your next manuscript at $\boldsymbol{\nabla}$ springeropen.com 